\section{Avaliação da implantação de atividades de prevenção das DST/AIDS na atenção básica: um estudo de caso na Região Metropolitana de São Paulo, Brasil}

\author{
Evaluating the implementation of STD/AIDS \\ prevention activities in primary health care \\ facilities: a case study in Greater Metropolitan \\ São Paulo, Brazil
}

Dulce Aurélia de Souza Ferraz ${ }^{1}$

Maria Ines Battistella Nemes 1

\section{Introdução}

Since the 1990s, international guidelines have recommended the incorporation of STD/AIDS prevention in primary care. In Brazil, the Ministry of Health has made investments to include such preventive activities. This in-depth case study is an evaluation of the implementation of these activities in a family health unit in Greater Metropolitan São Paulo. The study analyzed the unit's activities as a whole and the specific STD/ AIDS prevention activities by means of direct observations and semi-structured interviews with the unit's professional health staff. The unit's technological characteristics were similar to those of traditional Brazilian primary care services, with limited potential for achieving the principle of comprehensive care. STD/AIDS prevention activities had been incorporated, but were devoid of important technological meanings like dialogue and specific attention to users' uniqueness. This characteristic and others reveal a tension between the program's technological proposals and the current technological profile of primary care. However, the identification of this tension could favor reflection on new values in routine primary care, thereby favoring the achievement of more comprehensive technological arrangements.

Acquired Immunodeficiency Syndrome; Sexually Transmitted Diseases; Disease Prevention
A implantação de atividades de prevenção das DST/AIDS na rede de atenção básica do Sistema Único de Saúde (SUS) é um componente prioritário da política brasileira de controle desses agravos 1,2 .

Diferentemente das ações de assistência às pessoas vivendo com HIV/AIDS - que desde o início da epidemia estruturaram-se nos serviços do sistema - as atividades de prevenção centraram-se, inicialmente, nas ações realizadas por organizações da sociedade civil 3 . A proposta de sua integração às estruturas do SUS começou a ser intensamente debatida nos anos 1990, como resposta às tendências de heterossexualização e feminização da epidemia que se consolidavam à época 4.

Importantes impulsionadoras dessa proposta foram as reivindicações do movimento de mulheres, fortalecidas pelas recomendações da Plataforma de Ação da Conferência Internacional sobre População e Desenvolvimento 5, realizada em 1994, no Cairo, Egito. A plataforma propôs a inclusão da atenção às DST/AIDS entre as ações prioritárias de saúde reprodutiva dos países signatários, enfatizando a implantação nos serviços de atenção básica de atividades de prevenção, detecção e tratamento das DST; educação e aconselhamento para prevenção da AIDS; disponibilização de preservativos. 
Desde então, as atribuiçõoes dos serviços de saúde neste campo vêm se ampliando, como se pode verificar, em âmbito internacional, pelas recentes recomendações da Organização Mundial da Saúde ${ }^{6}$ sobre oferta da testagem anti-HIV, e, nacionalmente, pela amplitude de atividades de prevenção propostas pelo Ministério da Saúde para a atenção básica 7 .

O Brasil, atualmente, prioriza a Estratégia Saúde da Família como modelo de organização da atenção básica ${ }^{8}$. Considera-se que essa estratégia favorece a reorientação do modelo de atenção centrado no atendimento individualizado, no trabalho do médico e na doença, para um modelo que prioriza a qualidade de vida das pessoas, capaz de transformar e aprimorar a relação entre os profissionais de saúde e a comunidade (por meio do estabelecimento de vínculos de compromisso e co-responsabilidade) e de concretizar o princípio da integralidade ${ }^{8}$.

Embora a prevenção das DST/AIDS não esteja explicitamente estabelecida na Política Nacional de Atenção Básica como área prioritária 8, a integração dessas atividades na atenção básica consta em documentos referenciais do Programa Nacional de DST e AIDS (PN DST/AIDS) como "melhor alternativa para a prevenção de novas infecções e ... instrumento capaz de antecipar problemas individuais e coletivos em relação à epidemia de HIV e AIDS e a ocorrência de doenças sexualmente transmissiveis" 2.

Tomando como referência esses documentos, as atividades de prevenção cuja realização está prevista nos serviços de atenção básica podem ser agrupadas em: oferta de testagem voluntária e aconselhamento para população geral e para gestantes; disponibilização de preservativos; inclusão, nos serviços, dos segmentos populacionais mais vulneráveis; assistência às DST; orientações aos usuários em atividades cotidianamente realizadas nos serviços. Devem ser guiadas pelos princípios éticos que sustentam o componente de prevenção do PN DST/AIDS: respeito à diversidade sexual, à vivência da sexualidade e ao uso de drogas, com abordagens baseadas nos princípios de direitos humanos, participação social e na noção de vulnerabilidade, atentas às dimensões subjetivas da prevenção e aos contextos estruturantes da vida das pessoas e dos grupos 1 .

No cenário internacional, a implantação dessas atividades vem sendo amplamente debatida. Dentre as potencialidades apontadas, destacamse: ampliação da cobertura das ações de prevenção e tratamento das DST 9,10,11; apoio comunitário de que desfrutam os serviços de atenção básica 9; possibilidade de otimização de recursos humanos e estruturais 10. Como limitações des- se processo, identificam-se: diferenças entre as necessidades de saúde a que visam responder os tradicionais programas de saúde reprodutiva e os de prevenção das DST/AIDS 12; acréscimo de atividades clinicamente complexas à rotina dos profissionais 8; ausência de consenso entre os formuladores de políticas sobre atividades que seriam passíveis de integração 12 .

Estudos empíricos realizados no Brasil 13 e no mundo 14 têm constatado a redução do aconselhamento e das ações educativas de prevenção do HIV realizados em serviços de atenção básica ao repasse de informações. Complementarmente, estudos nacionais 15 e internacionais 16 mostram que mulheres com diagnóstico de AIDS, mesmo quando apresentavam histórico de risco de infecção, não se recordavam de ter recebido qualquer tipo de informação sobre HIV ou outras DST nos serviços que freqüentavam antes do diagnóstico, tendo, a maioria, descoberto a soropositividade quando do aparecimento de sintomas ou da morte por AIDS do companheiro ou filho.

Este trabalho busca explorar as possibilidades e os limites da integração das ações de prevenção das DST/AIDS na atenção operada numa unidade de atenção básica organizada pela Estratégia Saúde da Família. Assume como pressuposto a existência de tensionamentos entre os arranjos tecnológicos vigentes na atenção básica e as proposições ético-normativas das ações de prevenção das DST/AIDS no Brasil. Compreende-se que as possibilidades de implantação efetiva dessas ações em consonância com tais proposições serão dadas pelo maior ou menor potencial do modelo assistencial 17 em concretizar o valor da integralidade na dimensão das práticas de saúde 18 .

\section{Métodos}

Estudo realizado num município da região metropolitana de São Paulo, entre julho e outubro de 2006.

Baseia-se no conceito de organização tecnológica do trabalho em saúde 19,20, no modelo de avaliação da atenção básica desenvolvido a partir deste conceito 21 e em estudos empíricos de avaliação do PN DST/AIDS orientados por este modelo 22,23.

Neste referencial, o perfil tecnológico de um serviço de saúde é definido pela articulação entre os processos de trabalho nele predominantes. Estes resultam da dinâmica entre os objetos definidos para uma atividade (um jovem, por exemplo), sua finalidade (prevenir a AIDS, por exemplo) e os instrumentos que os profissionais utilizam para alcançá-la (orientação para uso de preservativo, por exemplo). Ressalta-se a re- 
produção de valores humanos que acontece no trabalho, sobretudo a que se dá mediante a utilização de instrumentos não materiais, como as orientações educativas.

Ao incorporar novas proposições (como atividades de prevenção da AIDS para jovens, por exemplo), a articulação existente entre os processos de trabalho é tensionada e modificada, produzindo uma reconstrução tecnológica do plano propositivo do trabalho.

Coerentemente com essa apreensão conceitual, o modelo avaliativo desta investigação baseia-se no contraste entre o plano ético-normativo do programa em estudo e seu plano operativo. Analisam-se as reconstruções que prioridades, normas de funcionamento e padrões de ação estabelecidos no plano propositivo do PN DST/AIDS sofrem ao serem transpostos para o plano concreto da atenção básica. Busca-se analisar, também, a implantação como um processo de encontros e desencontros da consecução de exercícios técnicos, valores e interesses que, ao ser estudado, deve permitir o questionamento das impropriedades apresentadas pelo plano propositivo à vida prática e não o inverso 24 .

A abordagem avaliativa é de avaliação de implantação 25 , recomendada no estudo de programas com pouca especificidade tecnológica, multiplicidade de estratégias, execução em contextos variados e pouca definição do grau desejável de sua efetivação ${ }^{26}$. A técnica é de estudo de caso em profundidade 27.

Visando a ampliar a validade dos achados, buscou-se eleger a unidade de saúde "melhor possível". Selecionou-se, primeiramente, o município, mediante consulta a dirigentes da Coordenação Estadual de DST/AIDS de São Paulo, com base nos critérios de existência de: Coordenação Municipal de DST/AIDS consolidada, serviços de atenção básica organizados pela Estratégia Saúde da Família e priorização local da implantação das atividades de prevenção das DST/AIDS na atenção básica.

A unidade de saúde foi selecionada por consulta à Coordenação Municipal de DST/AIDS e por visitas às três unidades indicadas como melhores. Selecionou-se a que relatou participação no processo de implantação das ações de prevenção realizado pela Coordenação Municipal de DST/AIDS, operação atual dessas atividades, espaço físico adequado e concordância da gerência em participar da pesquisa.

$\mathrm{O}$ estudo foi apresentado à equipe em reunião, na qual se obteve autorização para realizar as observações diretas. Para consultas, coleta do papanicolaou e visitas domiciliares, também foi solicitada autorização aos usuários e profissionais no momento da observação.
Considerando-se a perspectiva conceitual adotada, a unidade de saúde da família foi estudada em seu conjunto, a fim de mapear os momentos que compõem o cotidiano do processo de trabalho da equipe, tanto dentro quanto fora da unidade 28,29.

Para captação e análise das atividades específicas de prevenção das DST/AIDS, foram estabelecidos dois conjuntos tecnológicos: (1) atividades integradas a outras previamente realizadas no serviço e (2) atividades específicas de prevenção das DST/AIDS.

Para apreensão dessas dimensões, foram realizadas as seguintes atividades:

- Entrevista com gerente da unidade de saúde da família e com profissionais envolvidos nas atividades de prevenção das DST/AIDS: duas auxiliares de enfermagem, um médico e três agentes comunitários de saúde. A leitura e assinatura do Termo de Consentimento Livre e Esclarecido precederam todas as entrevistas, que foram realizadas na unidade de saúde, em horários previamente agendados com os profissionais, pela pesquisadora principal, com base em roteiro semi-estruturado. Foram gravadas sob autorização dos entrevistados e transcritas literalmente.

- Observação direta e sistemática do processo de trabalho e de componentes específicos, seguindo roteiro estruturado, durante 16 períodos (manhãs e tardes). Foram observados atendimento de recepção e sala de espera; consultas de enfermagem; coleta de Papanicolaou; visitas domiciliares; grupos de hipertensão e diabetes e de planejamento familiar; consultas médicas; reunião de equipe. As observações, feitas pela pesquisadora principal e por um pesquisador auxiliar, foram registradas num diário de campo.

A presença dos pesquisadores na unidade foi bem recebida em todos os momentos da investigação.

A consolidação das informações em dados de análise foi debatida entre os pesquisadores envolvidos, e a observação foi considerada a fonte mais fidedigna nos casos de divergência de informações. O material foi submetido à análise temática 27,30 .

Todos os procedimentos de pesquisa obedeceram à Resolução no . 196/96 do Conselho Nacional de Saúde. O estudo foi aprovado pelos Comitês de Ética em Pesquisa do Instituto de Saúde, Secretaria de Estado da Saúde de São Paulo e da Faculdade de Medicina, Universidade de São Paulo. 


\section{Resultados}

\section{Perfil tecnológico}

Criada em 2002, a unidade de saúde da família estudada localiza-se em região periférica do município, num bairro com áreas de favela. Inicialmente pertencia a outra unidade básica, que permanece ativa e atende aos moradores de fora da área de abrangência da unidade de saúde da família. Ganhou sede própria em 2005 e, no período do estudo, funcionava numa sede recém inaugurada, em reforma, composta por sala de espera; recepção; consultório médico; consultório de enfermagem; salas de coleta, medicação, imunização e inalação; farmácia, e sala de grupo (em construção). Os atendimentos são realizados de segunda a sexta-feira, das $7 \mathrm{~h} 30$ às 17h.

É constituída por uma equipe mínima de saúde da família: médico, enfermeiro, duas auxiliares de enfermagem, oito agentes comunitários de saúde, uma auxiliar administrativa e uma auxiliar de serviços gerais. A gerência é exercida pelo enfermeiro.

A clientela segue o perfil tradicional dos serviços de atenção básica, sendo composta majoritariamente por mulheres em idade reprodutiva, crianças e idosos, principalmente portadores de diabetes e hipertensão arterial. Homens jovens raramente são vistos na unidade.

Os usuários são cadastrados pelos agentes comunitários de saúde mediante comprovação de residência há, no mínimo, quatro meses na área adstrita. Moradores de áreas vizinhas que não pertencem à área de adstrição podem ter acesso a serviços pontuais (Figura 1).

A área divide-se em oito micro-áreas, cada uma sob responsabilidade de um agente comunitário de saúde. As micro-áreas concentram entre 180 e 250 famílias, variação que ocorre porque a distribuição dos agentes comunitários de saúde dá-se por ruas predefinidas pela Secretaria Municipal de Saúde (SMS). Conseqüentemente, agentes comunitários de saúde que atuam nas áreas de habitação mais precárias (casas sobrepostas, habitação conjunta de famílias) acompanham maior número de famílias.

As atividades oferecidas também são similares às das demais unidades de atenção básica, exceto pelo acréscimo das visitas domiciliares, feitas pelos agentes comunitários de saúde para todas as famílias e, para casos específicos, pelo enfermeiro, auxiliares de enfermagem (curativos, medicação) e médico (usuários acamados).

A Figura 1 detalha as atividades ofertadas pelas unidades de saúde da família.

Visitas dos agentes comunitários de saúde são realizadas mensalmente, mas, para usuários com algum dos agravos ou condições prioritárias do Programa Saúde da Família (PSF), são realizadas duas visitas mensais. As visitas são anotadas num caderno, assinado pelo usuário, contudo, freqüentemente, os moradores não são encontrados nas casas; nesse caso, os agentes comunitários de saúde, a fim de atestar sua ida ao domicílio, solicitam a parentes ou a vizinhos que assinem o caderno.

Os agentes comunitários de saúde relatam insuficiência das visitas domiciliares do médico, realizadas somente às sextas-feiras à tarde, com agendamento feito por eles e quase exclusivamente para acamados. Alegam não serem atendidas muitas vezes e relatam inadequações do procedimento: [agentes conversando na área externa da USF] "A gente tem que conversar na reunião sobre a visita do médico... a gente aprendeu no curso que médico da família não é assim, não é só pra visitar quem já tá acamado... quem já tá assim... dificilmente vai sair desse estado. Ele tem que fazer visita pra evitar que as pessoas fiquem assim" (Relato de observação).

Consultas médicas são as únicas atividades que requerem agendamento prévio. Dividem-se em puericultura, pediatria, hebiatria, ginecologia, obstetrícia e queixas variadas. Não há dias fixos para esses atendimentos, porém são garantidos dois ou três períodos por mês na agenda para cada grupo, ficando os demais períodos para atendimentos de queixas variadas.

Para cada período de quatro horas são agendadas doze consultas. Quatro vagas são deixadas para "encaixe" de usuários não agendados, que são triados na consulta de enfermagem.

As consultas médicas são rápidas, resumindo-se à abordagem da demanda considerada principal pelo médico, anamnese restrita a poucas perguntas, exame físico focalizado e prescrição de medicamentos ou encaminhamentos. Esclarecimentos sobre diagnóstico são sumários e com uso de linguagem exclusivamente técnica. Observa-se pouca interação e pouca abertura para escuta dos usuários: [consulta de adolescente, primeira vez, queixa de corrimento vaginal há mais de ano]:

Médico: "Tem coceira na vagina, a vagina arde?".

Usuária: "Às vezes arde; coceira, não".

Médico: "Dor?"

Usuária: “Não”.

[Faz exame físico].

Médico: "Você vai tomar uns comprimidos, seu namorado também. Vai usar creme ginecológico".

Usuária: "U-hum”.

[Ensina a posologia. Vários segundos de silêncio enquanto ele escreve e ela fica olhando]. 


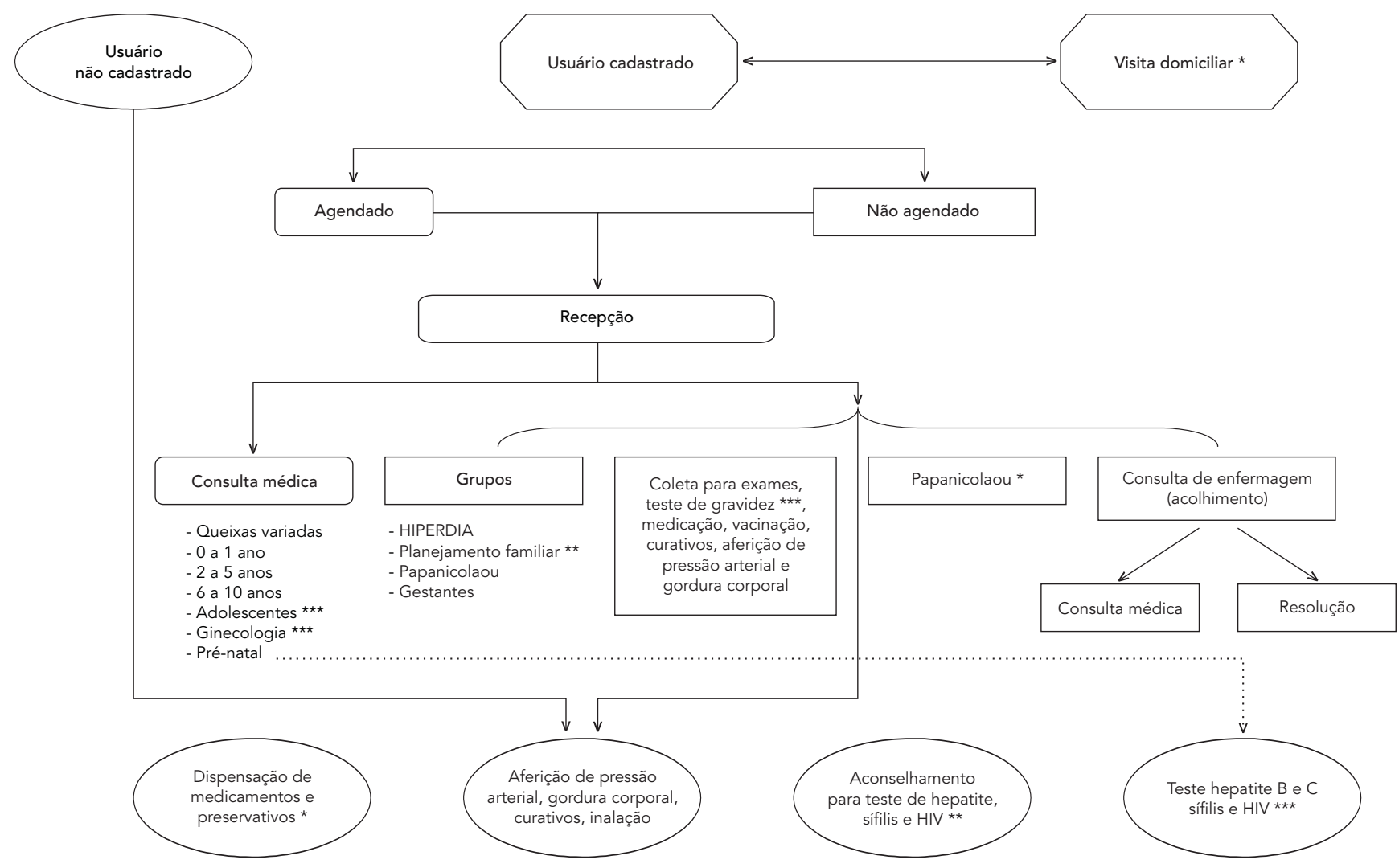

\footnotetext{
* Atividades que abordam prevenção das DST/AIDS quando há demanda.

** Atividades relacionadas à prevenção das DST/AIDS.

*** Atividades que não abordam prevenção das DST/AIDS mesmo quando há demanda.

HIPERDIA: Sistema de Cadastramento e Acompanhamento de Hipertensos e Diabéticos.
}

Médico: “Aqui tem pra vocêe pro seu namorado. Quando acabar o tratamento, marca preventivo na recepção".

[Observação da pesquisadora: a usuária não havia relatado parceria fixa].

A coleta de papanicolaou, feita pelas auxiliares de enfermagem, não requer agendamento e é oferecida diariamente. Os requisitos para realização do procedimento são mais rígidos do que os estabelecidos pelo Ministério da Saúde: ausência de menstruação, não utilização de pomadas ginecológicas ou anticoncepcionais locais e abstinência sexual nas 72 horas anteriores, em vez das 48 oficialmente recomendadas 31 . Aconselha-se explicitamente que as usuárias tomem banho no dia da coleta.
Todos os grupos realizados no serviço são abertos. As datas não são fixas, são agendadas mês a mês e informadas aos usuários nas visitas domiciliares das agentes comunitárias de saúde e no calendário mensal, afixado no mural da recepção da unidade de saúde da família.

O grupo de hipertensão e diabetes é o que acontece mais sistematicamente. Conduzido pelo agente comunitário de saúde responsável pela micro-área, acompanhado de enfermeiro, auxiliar ou médico, restringe-se à aferição da pressão ou da glicemia dos usuários, conferência da receita médica e entrega dos medicamentos. Algumas orientações são dadas enquanto os atendimentos são feitos, mas parecem ser pouco valorizadas: [A caminho do espaço onde será realizado o grupo, a agente comunitária de saúde 
pede ao enfermeiro]: "Você segura o povo, senão eles só querem pegar o remédio e ir embora”.

No dia em que o grupo foi observado, foram atendidas 51 pessoas em cerca de uma hora. As orientações caracterizaram-se pelo tom prescritivo e, por vezes, ameaçador: [Durante o grupo, enfermeiro relata que a mãe de uma ex-colega de trabalho faleceu em decorrência de um acidente vascular cerebral e diz, em voz alta]: "É bom pro nossos pacientes ouvirem, a gente fala da pressão alta, ninguém acredita, fica tudo enchendo a cara de vinho, de mocotó... que na casa... tinha uma feijoadinha e não resistiu".

Os demais grupos deveriam, segundo estabelecido pela Secretaria Municipal de Saúde local, ter periodicidade mensal, mas freqüentemente são cancelados. Durante os três meses e meio de campo, ocorreram apenas dois grupos de planejamento familiar e um de Papanicolaou, realizados de maneira improvisada na sala de consulta de enfermagem. Não foram realizados grupos de gestantes ou adolescentes, cuja existência fora relatada pela equipe.

Quanto às reuniões de equipe, apenas uma foi realizada no período do estudo.

\section{Atividades de prevenção das DST/AIDS}

- Atividades integradas a outras previamente existentes na unidade de saúde da família

a) Orientações nas atividades gerais

Segundo os profissionais entrevistados, as atividades de prevenção das DST/AIDS consistem em orientações que são realizadas por todos, nas mais diversas atividades, pois estão previstas pela Estratégia Saúde da Família e são abordadas nas capacitações introdutórias das equipes:

"Eu falo sempre sobre preservativo, sobre troca de parceiro, lógico, se a pessoa me dá liberdade. Por exemplo, se tem uma pessoa que eu sei que tem vários parceiros, mas ela não me falou, eu vou falar de uma forma pra não ofender a pessoa, pra que ela não se sinta mal, mas eu vou falar do preservativo..." (agente comunitária de saúde).

"Se eu vir que a pessoa tá numa idade que tá praticando sexo, se eu vir qualquer problema, se eu vir essas doenças sexualmente transmissiveis, eu pergunto, 'Ah, é um problema assim e tal, você já foi em algum lugar? Já passou pelo médico?', esse tipo de coisa" (agente comunitária de saúde).

Os profissionais não referiram existência de protocolos ou supervisão específica para essas orientações. Exceção foi o médico, que referiu utilizar os protocolos que são apresentados nas capacitações realizadas pela Secretaria Municipal de Saúde. b) Grupo de planejamento familiar

Dos dois grupos realizados, somente um pôde ser observado. O número de participantes restringiu-se a três mulheres, o que, segundo relatos da equipe, vinha sendo a média habitual.

O enfermeiro, responsável pela condução do grupo, enfatizou o preservativo masculino como o método contraceptivo mais seguro:

"Quando a gente fala de planejamento familiar... o método mais seguro atualmente é a camisinha. Por quê? Porque ela protege contra a gravidez e contra as DST... Vocês sabem que uma das piores doenças que a gente tem hoje é o HIVI AIDS... Tem muitos casos que o rapaz chega lá 'eu te amo, você é minha flor', mas não pode confiar. A gente ainda vive numa sociedade que os homens não querem se prevenir... por causa do machismo... Tem que se prevenir, porque enquanto vocês ficam o dia inteiro no tanque, no fogão, fazendo comidinha fresquinha pro marido, de repente ele encontra uma cabrita lá fora e você, inocentemente, no ato sexual, pega uma DST" (Enfermeiro).

Ao final do grupo, verificou-se que as três participantes já haviam optado pela esterilização cirúrgica. Sua participação na atividade se dava por ser este um procedimento necessário para obtenção da autorização da cirurgia.

c) Coleta de Papanicolaou

Observou-se realização de questionamentos em relação à vida sexual das usuárias durante as coletas, seguindo o formulário do Programa Viva Mulher 31. A auxiliar informou sobre as sorologias oferecidas na unidade e questionou o uso do preservativo nas relações sexuais:

Auxiliar: "O que você usa pra evitar a gravidez?".

Usuária: "Nada".

Auxiliar: "Não tá tendo relação?".

[Silêncio]

Auxiliar: "Quanto tempo tem que você não mantém relação?”.

Usuária: "Uns seis meses".

Auxiliar: "E quando tem relação você usa preservativo?”.

Usuária [concordando]: " $A-h \tilde{a}$ ".

Auxiliar: "Nós estamos fazendo alguns exames, são de graça, se você ficar interessada, exame que consta se a mulher tem hepatite B, C, HIV.Não teve aquele programa 'Fique sabendo'?.. Que tem muitas pessoas que têm dúvida e têm medo de fazer, né?... Eu falo porque quem tiver interessado, às vezes não vê a plaquinha, é só falar com o enfermeiro, tá?".

Usuária [concordando]: “A-hã". 
d) Visitas domiciliares das agentes comunitárias de saúde

Nas visitas realizadas pelas agentes comunitárias de saúde, o tema das DST/AIDS foi abordado quando se identificaram casos de DST ou situações interpretadas pelo agente como "de risco":

Agente comunitária: " $E$ a $K$ [enteada da usuária atendida]?”

Usuária: "Tá dando trabalho. Tá com outro namoradinho agora... entra pra casa todo dia 1 h30 da manhã. O pai já não sabe mais o que faz. Aquele menino, o V., ele não que nem ver, que diz que foi ele que desvirginou ela, ainda bem que num [faz sinal de barriga de gravidez]. Mas o médico já disse que ela não é mais virgem, não".

Agente comunitária de saúde: "É... sem falar que tem também as doenças sexualmente transmissiveis, né?".

Usuária: “É, né?".

Agente comunitária de saúde: "É, muitas vezes as famílias acham que não vai acontecer com elas, aí de repente, aparece uma AIDS, uma DST".

Usuária: "Ai, Deus me livre, é verdade, nem fale!".

Agente comunitária de saúde: "As meninas são terríveis, não se previnem".

Usuária: "Deviam ter bastantes palestras pra elas, né?".

Agente comunitária de saúde: "Mas a gente faz! Vai na escola, tudo, só que não adianta!”.

Usuária: "Não adianta mesmo, né? Agora não sei o que a gente faz".

e) Consultas ginecológicas e de adolescentes

Essas consultas merecem destaque porque, embora tenham sido comuns as queixas de DST, não foi observada a realização de quaisquer orientações sobre uso de preservativos ou qualquer outra forma de prevenção das DST/AIDS nesses atendimentos. Para mulheres com esse tipo de queixa, observou-se, inclusive, prescrição de outros métodos contraceptivos, especialmente os hormonais:

[Consulta de usuária com condiloma reincidente. Após exame ginecológico, médico comenta com pesquisadora enquanto a usuária se veste no banheiro].

Médico: "Doença sexualmente transmissível, vou te contar. Essa é portadora de um HPV, o marido já tem há um tempão. Promiscuidade, viu!".

[Quando a usuária volta, solicita ao médico].

Usuária: "O senhor pode colocar o anticoncepcional aí na receita, que o meu acabou?".

Médico: "Qual você toma?"

Usuária: "Microvlar".
[Médico redige receita de anticoncepcional e pomada. Orienta a não ter relações durante o tratamento da DST].

Foram recorrentes também recomendações para que mulheres com DST "convencessem" seus parceiros a se tratarem, mesmo sabendo o médico da dificuldade que isso representaria para as usuárias:

Médico [redigindo a receita]: "Seu namorado, sem choro nem vela, vai ter que tomar remédio também. Eu digo isso porque homem é mais resistente, diz que o problema é com você".

Usuária: "Pode deixar".

[Silêncio].

Médico: "Qual o nome do seu noivo?".

[Faz uma receita para ambos, explica posologia].

Médico: "E pra que não haja recorrência, seu noivo tem que tomar, senão você toma, melhora, aí o que acontece? Na primeira relação, volta tudo".

\section{- Atividades específicas de prevenção das DST/AIDS}

a) Sorologias para HIV, sífilis e hepatites B e C

As sorologias foram implantadas em junho de 2005 na unidades de saúde da família e estão disponíveis a todos os usuários, inclusive àqueles não cadastrados. A procura pelo procedimento é pequena; embora os profissionais relatem crescimento da demanda, os mapas de produtividade consultados atestavam a realização de apenas 14 testes em três meses.

O enfermeiro é o responsável exclusivo pela atividade e relata ter recebido supervisões específicas da Coordenação Municipal de DST/AIDS, nas quais pôde dirimir dúvidas.

O aconselhamento pré-teste consiste no preenchimento de formulário fornecido pela Coordenação Municipal de DST/AIDS, versão simplificada do utilizado nos centros de testagem e aconselhamento, com questões sobre parcerias sexuais, uso de preservativos e uso de drogas. É preenchido e enviado para a Coordenação Municipal de DST/AIDS.

Para gestantes, segundo o enfermeiro, não é realizado aconselhamento. Pôde-se observar a entrega do resultado do exame anti-HIV feita pelo médico durante a consulta de pré-natal, juntamente com os demais exames solicitados. Os resultados foram informados sem que se explicitassem seu significado ou que fossem realizadas quaisquer orientações preventivas.

A unidade de saúde da família já diagnosticou casos de hepatites B e C. Nunca diagnosticou um caso de HIV, mas, se isso acontecer, o proce- 
dimento para entrega do resultado do exame é o encaminhamento do usuário para a referência: “Eu não dou esse resultado na mão do paciente, porque eu não sei se ele pode se jogar na frente dum carro aqui na frente. Eu falo para ele 'vai buscar seu resultado que está pronto'e lá [na referência] tem controle, tem psicólogos que podem dar suporte" (enfermeiro).

b) Dispensação de preservativos masculinos

Os preservativos masculinos estão disponíveis na farmácia. A unidade já teve preservativos femininos, mas deixou de tê-los porque não havia procura e a validade de vários deles expirou.

Para acessar os preservativos, os usuários devem cadastrar-se e receber um cartão específico, cujo objetivo é controlar a quantidade retirada mensalmente. São ofertados 12 preservativos por mês para cada usuário e 90 por mês para profissionais do sexo (os quais a equipe relata não ter entre a clientela da unidade de saúde da família). Usuários não cadastrados podem retirar quantidades menores.

Não foi observada entrega desses insumos em nenhum atendimento (individual ou grupal) da unidade de saúde da família. Os profissionais relatam haver pouca demanda por preservativos: "[Os usuários procuram] muito pouco, nós temos preservativo sobrando e aqui não tem esse negócio de só dar para cadastrado. Aqui chegou, pode ser adolescente, mesmo não cadastrado, ele leva se quiser" (auxiliar 1).

"Eu acho que (procuram) pouco, pelo número de pacientes que a gente tem. Tem gente que pega num mês, depois volta duas ou três vezes, mas também tem parceiro que não gosta. A gente ouve relatos das pacientes... 'Ah, meu parceiro não gosta'” (auxiliar 2).

\section{Discussão}

A atenção básica, especialmente a Estratégia Saúde da Família, tem sido objeto de muitos estudos avaliativos que abordam várias de suas dimensões 32,33 . Aqueles que se debruçam sobre o plano operativo do trabalho nas unidades apontam questões semelhantes às aqui encontradas: insuficiência dos recursos humanos 34; insipiência tecnológica e burocratização do trabalho dos profissionais 35 ; dificuldades na articulação técnica do trabalho 36; determinação da tradicional oferta de serviços sobre a demanda 37 ; baixa priorização de atividades preventivas 38 ; e dificuldades na abordagem e resolução de problemas de saúde associados a "temas tabus", como a sexualidade 29 .
Nos achados desse estudo, foi possível distinguir dois tipos de tensionamento no processo de implantação das ações de prevenção das DST/ AIDS nos serviços de atenção básica. O primeiro, relatado em outros estudos sobre a saúde da família ${ }^{38}$, refere-se ao desafio da superação da fragmentação em prol da integralidade das práticas de saúde. Esta é uma dimensão já expressa em discussões sobre modelos tecnológicos de organização da atenção básica, como as ações programáticas 20 e a vigilância em saúde 17 , que a saúde da família vem recrudescer no plano das práticas. Embora longe de superar esse desafio, o modelo confronta os serviços de saúde com necessidades da comunidade que requerem uma atuação que transcenda a abordagem estritamente biomédica. No entanto, faltam aos serviços, além de questões estruturais básicas, como profissionais em quantidade suficiente e espaços físicos adequados, dispositivos tecnológicos específicos, isto é, instrumentos e saberes que lhes permitam operacionalizar a atenção integral.

O segundo tensionamento é entre valores éticos que orientam as atividades de prevenção das DST/AIDS no Brasil e valores normativos verificados nas práticas da unidade de saúde da família. A pouca definição tecnológica, no campo programático, sobre como as atividades de prevenção das DST/AIDS devem ser implantadas favorece abordagens pautadas por conhecimentos não técnicos, com base no senso comum, freqüentemente orientadas pela moral e pelas características individuais de cada profissional.

Observam-se concepções de prevenção semelhantes nos discursos e práticas dos diferentes profissionais: todos consideram a prevenção o componente central do trabalho e relatam as orientações como parte importante dos atendimentos. Alguns se mostram mais empenhados em efetivar esta concepção, caso das auxiliares nas coletas, das agentes comunitárias de saúde nas visitas e do enfermeiro nos grupos; as consultas médicas são os momentos em que se verifica menor empenho neste sentido.

As atividades de educação em saúde, como grupos de planejamento familiar e de hipertensão e diabetes, representam mais alternativas para atendimento em massa dos usuários do que espaços de diálogo e interação. Refletindo sua baixa priorização, ocorrem esporadicamente e com freqüentes cancelamentos.

Abordagens preventivas realizadas nos atendimentos primam exclusivamente pela prescrição de condutas, recorrendo, inclusive, a ameaças como forma de "convencimento". Abre-se pouco espaço para discussão de dificuldades de ordem subjetiva ou social que possam estar atreladas ao cumprimento de tais condutas. 
Nos atendimentos essencialmente preventivos, como coletas de citologia e grupo de planejamento familiar, a abordagem do uso do preservativo e do risco de infecção por DST é genérica e normativa. As usuárias raramente têm oportunidade de falar sobre suas vivências e, quando o fazem, as informações por elas prestadas não se refletem na discussão de recomendações específicas, adequadas às suas necessidades singulares.

A abordagem das DST é exemplar da fragmentação das atividades curativas e preventivas. O tratamento, procurado quase exclusivamente por mulheres, é tecnicamente simplificado, resumido à prescrição medicamentosa e ao diálogo restrito e pouco claro sobre o diagnóstico. Não são discutidos modos de transmissão nem métodos de prevenção. Inexistem mecanismos para comunicação e tratamento de parceiros, sendo essa responsabilidade transferida às mulheres.

Tem-se, em síntese, a persistência de um arranjo tecnológico centrado na assistência médica individual, na abordagem exclusiva da dimensão biológica do adoecimento e na execução de práticas curativas e prescritivas que impede a incorporação de atividades preventivas em geral. No caso das DST/AIDS, esse arranjo, somado à já bastante estudada dificuldade dos profissionais de saúde em discutir claramente a vivência da sexualidade e, mais ainda, as questões de gênero nela implicadas, conflita com os referenciais ético-normativos que têm fundamentado a proposição destas atividades pelo PN DST/AIDS.

Avanços importantes merecem menção: a disponibilização de sorologias para HIV, hepatites B e C e sífilis e de preservativos masculinos para população geral. Entretanto, também se observa nessas atividades um esvaziamento de sua finalidade preventiva. Como verificado em outros estudos 13, o aconselhamento, ação central para a prevenção no programa de AIDS, reduz-se ao preenchimento de um formulário e à prescrição de condutas.

Importante destacar também, que desde o início deste século, a rede básica vem desempenhando importante papel na redução da transmissão vertical do HIV no Brasil, por meio da expressiva ampliação da testagem para o HIV de gestantes no pré-natal 39. Acertadamente, o PN DST/AIDS tem buscado ampliar este papel.

Achados como a importância dada pelos profissionais - ainda que no plano discursivo - à acessibilidade dos insumos de prevenção ou ao respeito aos limites postos pelos usuários na abordagem das questões referentes à sexualidade, permitem-nos considerar que o tensionamento provocado pela implantação de atividades de prevenção das DST/AIDS pode, ainda que não alcance sua efetividade potencial máxima, representar um avanço na direção da integralidade. Mais do que uma demanda adicional às já sobrecarregadas unidades de saúde da família, essas atividades, ao proporcionarem a "invasão" do cotidiano da atenção básica por questões complexas, como a sexualidade, e por novos valores, como o sigilo, tensionam o modelo predominante. Podem, assim, provocar produtivos questionamentos aos serviços acerca de suas insuficiências em objetivar as proposições éticonormativas do modelo que os orienta e contribuir para a concretização de novos e melhores arranjos tecnológicos. O investimento na implantação e na maior definição tecnológica das ações no campo programático pode representar o diferencial necessário para que esta potencialidade se efetive. 


\section{Resumo}

Desde os anos 1990, a incorporação da prevenção das DST/AIDS na atenção básica é internacionalmente recomendada. No Brasil, investimentos para essa incorporação vêm sendo feitos pelo Ministério da Saúde. Esta pesquisa realiza uma avaliação da implantação dessas atividades, mediante estudo de caso em profundidade, realizado numa unidade de saúde da família da Região Metropolitana de São Paulo. Analisam-se o conjunto das atividades da unidade e aquelas específicas de prevenção das DST/AIDS, por meio de observações diretas e entrevistas semi-estruturadas com profissionais do serviço. Verifica-se que o perfil tecnológico da unidade se assemelha ao dos tradicionais serviços da atenção básica brasileiros, apresentando limitado potencial de concretização do princípio da integralidade. Incorporam-se atividades de prevenção das DST/ AIDS, porém esvaziadas de importantes sentidos tecnológicos, como o diálogo e a atenção à singularidade dos usuários. Esta e outras características revelam um tensionamento entre as propostas tecnológicas do programa e o perfil tecnológico atual da atenção básica. Entretanto, a explicitação desse tensionamento pode favorecer a reflexão sobre novos valores no cotidiano da atenção básica, potencializando a concretização de arranjos tecnológicos mais integrais.

Síndrome de Imunodeficiência Adquirida; Doenças Sexualmente Transmissíveis; Prevenção de Doença

\section{Referências}

1. Ministério da Saúde. Plano Estratégico do Programa Nacional de DST/AIDS - 2005. http://bvsms. saude.gov.br/bvs/publicacoes/plano_estrategico. pdf (acessado em 24/Out/2006).

2. Ministério da Saúde. Plano Estratégico 2004-2007. http://bvsms.saude.gov.br/bvs/publicacoes/ plano_estrategico_dstaids.pdf (acessado em 02/ Nov/2005).

3. Parker R. Estado e sociedade em redes: descentralização e sustentabilidade das ações de prevenção das DST/AIDS In: Parker R, Terto Jr. V, Pimenta MC, organizadores. Aprimorando o debate: respostas sociais frente à AIDS. Rio de Janeiro: Associação Brasileira Interdisciplinar de AIDS; 2002. p. 31-6.

4. Diniz SG, Villela WV. Interfaces entre os programas de AIDS e saúde reprodutiva: o caso brasileiro. In: Parker R, Galvão J, Bessa MS, organizadores. Saúde, desenvolvimento e política. Respostas frente à AIDS no Brasil. Rio de Janeiro: Editora 34/Associação Brasileira Interdisciplinar de AIDS; 1999. p. 177-224.

5. United Nations. Report of the International Conference on Population and Development. New York: United Nations; 1995.

\section{Colaboradores}

As autoras participaram das etapas de concepção, análise, redação e revisão final do artigo.

\section{Agradecimentos}

Agradecemos a todas as participantes e orientadoras do XII Programa de Introdução à Metodologia de Pesquisa em Gênero, Sexualidade e Saúde Reprodutiva, com base no qual este estudo foi desenvolvido; a César Inoue, pela colaboração no trabalho de campo e organização dos dados para análise; à Dra. Regina Maria Barbosa, pelas contribuições à elaboração e desenho do estudo; e à Prof. Dra. Lilia Blima Schraiber, pelas colaborações ao desenho do estudo e à elaboração do plano de análise.
6. World Health Organization. Guidance on providerinitiated HIV testing and counseling in health facilities. Geneva: United Nations Joint Programme on HIV/AIDS/World Health Organization; 2007.

7. Ministério da Saúde. HIV/AIDS, hepatites e outras DST. Brasília: Ministério da Saúde; 2006. (Cadernos de Atenção Básica 18).

8. Brasil. Portaria $n^{\circ} .648$. Aprova a Política Nacional de Atenção Básica, estabelecendo a revisão de diretrizes e normas para a organização da atenção básica para o Programa Saúde da Família (PSF) e o Programa Agentes Comunitários de Saúde (PACS). Diário Oficial da União 2006; 28 mar.

9. Lush L. Service integration: an overview of policy developments. Int Fam Plan Perspect 2002; 28:71-5.

10. Germain A, Kidwell J. The unfinished agenda for reproductive health: priorities for the next 10 years. Int Fam Plan Perspect 2005; 31:90-3.

11. Askew I, Berer M. The contribution of sexual and reproductive health services to the fight against HIV/AIDS: a review. Reprod Health Matters 2003; 11:51-73.

12. Caldwell JC, Caldwell P. Is integration the answer for Africa? Int Fam Plan Perspect 2002; 28:108-10. 
13. Feliciano KVO, Kovacs MH. As necessidades comunicacionais das práticas educativas na prevenção da transmissão materno-fetal do HIV. Rev Bras Saúde Matern Infant 2003; 3:393-400.

14. Richey LA. HIV/AIDS in the shadows of reproductive health interventions. Reprod Health Matters 2003; 11:30-5.

15. Vermelho LL, Barbosa RHS, Nogueira SA. Mulheres com AIDS: desvendando histórias de risco. Cad Saúde Pública 1999; 15:369-79.

16. Madge S, Olaitan A, Mocroft A, Phillips A, Johnson M. Access to medical care one year prior to diagnosis in 100 HIV-positive women. Fam Pract 1995; 14:255-7.

17. Paim J. A reforma sanitária e os modelos assistenciais. In: Rouquayrol MZ, Almeida Filho N, organizadores. Epidemiologia e saúde. 5a Ed. Rio de Janeiro: MEDSI; 1999. p. 455-66.

18. Mattos RA. Os sentidos da integralidade: algumas reflexões acerca de valores que merecem ser defendidos. In: Pinheiro R, Mattos RA, organizadores. Os sentidos da integralidade na atenção e no cuidado à saúde. Rio de Janeiro: Instituto de Medicina Social, Universidade do Estado do Rio de Janeiro/ABRASCO; 2001. p. 39-64.

19. Mendes-Gonçalves RB. Tecnologia e organização social das práticas de saúde. Características tecnológicas de processo de trabalho na rede estadual de centros de saúde de São Paulo. São Paulo: Editora Hucitec; 1994.

20. Nemes MIB. Prática programática em saúde. In: Schraiber LB, Nemes MIB, Mendes-Gonçalves $\mathrm{RB}$, organizadores. Saúde do adulto: programas e ações na unidade básica. 2a Ed. São Paulo: Editora Hucitec; 2000. p. 48-65.

21. Nemes MIB. Avaliação do trabalho programático na atenção primária à saúde [Tese de Doutorado] São Paulo: Faculdade de Medicina, Universidade de São Paulo; 1995.

22. Castanheira ERL. Avaliação da assistência ambulatorial a pessoas vivendo com HIV/AIDS em serviços públicos no Estado de São Paulo: relações entre qualidade e organização do processo de trabalho [Tese de Doutorado]. São Paulo: Faculdade de Medicina, Universidade de São Paulo; 2002.

23. Britto-Alves MTS. Avaliação da assistência ambulatorial a pessoas vivendo com HIV e AIDS no Sistema Único de Saúde: a situação no Maranhão [Tese de Doutorado]. São Paulo: Faculdade de Medicina, Universidade de São Paulo; 2003.

24. Schraiber LB. Prefácio. In: Hartz ZMA, organizadora. Avaliação em saúde: dos modelos conceituais à prática na análise da implantação de programas. Rio de Janeiro: Editora Fiocruz/ABRASCO; 1997. p. 9-15.

25. Hartz ZMA, organizadora. Avaliação em saúde: dos modelos conceituais à prática na análise da implantação de programas. Rio de Janeiro: Editora Fiocruz; 1997.

26. Nemes MIB. Avaliação em saúde: questões para os programas de DST/AIDS no Brasil. Rio de Janeiro: Associação Brasileira Interdisciplinar de AIDS/Instituto de Medicina Social, Universidade do Estado do Rio de Janeiro; 2001. (Série Fundamentos de Avaliação, 1).
27. Minayo CMS. O desafio do conhecimento. Pesquisa qualitativa em saúde. 8a Ed. São Paulo: Editora Hucitec; 2004.

28. Sala A, Nemes MIB, Cohen DD. A avaliação na prática programática. In: Schraiber LB, Nemes MIB, Mendes-Gonçalves RB, organizadores. Saúde do adulto. São Paulo: Editora Hucitec; 2000. p. 173-93.

29. Schraiber LB. Equidade de gênero e saúde: o cotidiano das práticas no Programa Saúde da Família do Recife. In: Villela WV, Monteiro S, organizadores. Gênero e saúde. Programa de Saúde da Família em questão. Rio de Janeiro: ABRASCO/Fundo de População das Nações Unidas; 2005. p. 39-61.

30. Deslandes SF. Concepções em pesquisa social: articulações com o campo da avaliação em serviços de saúde. Cad Saúde Pública 1997; 13:103-7.

31. Instituto Nacional de Câncer. Programa nacional de controle do câncer do colo do útero e de mama - viva mulher. http://www.inca.gov.br/conteudo_ view.asp?id=140 (acessado em 03/Nov/2006).

32. Szwarcwald CL, Mendonça MHM, Andrade CLT. Indicadores de atenção básica em quatro municípios do Estado do Rio de Janeiro, 2005: resultados de inquérito domiciliar de base populacional. Ciênc Saúde Coletiva 2006; 11:643-55

33. Viana ALD, Rocha JSY, Elias PE, Ibañez N, Novaes, MHD. Modelos de atenção básica nos grandes municípios paulistas: efetividade, eficácia, sustentabilidade e governabilidade. Ciênc Saúde Coletiva 2006; 11:577-606.

34. Conill EM. Políticas de atenção primária e reformas sanitárias: discutindo a avaliação a partir da análise do Programa Saúde da Família em Florianópolis, Santa Catarina, Brasil, 1994-2000. Cad Saúde Pública 2002; 18 Suppl:S191-202.

35. Nascimento MS, Nascimento MAA. Prática da enfermeira no Programa de Saúde da Família: a interface da vigilância da saúde versus as ações programáticas em saúde. Ciênc Saúde Coletiva 2005; 10:333-45.

36. Silva IZQJ, Trad LAB. O trabalho em equipe no PSF: investigando a articulação técnica e a interação entre os profissionais. Interface Comun Saúde Educ 2005; 9:25-38.

37. Figueiredo W. Assistência à saúde dos homens: um desafio para os serviços de atenção primária. Ciênc Saúde Coletiva 2005; 10:105-9.

38. Escorel S, Giovanella L, Mendonça MHM, Senna MCM. O Programa de Saúde da Família e a construção de um novo modelo para a atenção básica no Brasil. Rev Panam Salud Pública 2007; 21: 164-76.

39. Brito AM, Sousa JL, Luna CF, Dourado I. Tendência da transmissão vertical de Aids após terapia anti-retroviral no Brasil. Rev Saúde Pública 2006; 40 Suppl:18-22.

Recebido em 23/Jan/2007

Versão final reapresentada em 02/Mai/2008

Aprovado em 19/Mai/2008 